\title{
EU SOU PRISIONEIRO DO KRENAK ${ }^{1}$
}

\section{ANTONIO HILARIO AGUILERA URQUIZA ${ }^{2}$}

$U F M S$

\author{
SÔNIA ROCHA LUCAS ${ }^{3}$
}

$M E C / S E C A D I$

\begin{abstract}
RESUMO: $O$ Texto apresenta um fragmento da dissertação de mestrado em Antropologia Sociocultural, a qual foi um estudo a partir do olhar da criança indígena acerca da atual situação do processo de regularização fundiária dos Kaiowá e Guarani no estado de Mato Grosso do Sul (retomada Pakurity). Entre os relatos para a pesquisa, o líder indígena fez questão que constasse a sua passagem pelo Reformatório Agrícola Indígena Krenak - Minas Gerais. A partir desta solicitação, elegemos como objetivo desse trabalho apresentar uma das diversas histórias vivenciadas pelos indígenas durante a ditadura militar. Os procedimentos metodológicos foram o trabalho de campo e, a partir dele, a observação participante, diário de campo e outras formas de registros. Podemos dizer que os relatos dos indígenas, em específico do sr. Bonifácio, liderança na retomada, trazem luz às violências e aos abusos sofridos em forma de prisões ilegais, violências físicas, trabalhos forçados e até remoção - seja forçada ou sob coação e esbulho - de suas terras tradicionais. Trazer à memória um dos diversos casos de indígenas presos no Krenak é não permitir o esquecimento das violências praticadas pelo Estado brasileiro, que devem ser reparadas.
\end{abstract}

PALAVRAS-CHAVE: violência; ditadura; Reformatório Krenak; território; direitos indígenas.

ABSTRACT: The text presents a fragment of a master's thesis in Sociocultural Anthropology, the study of the indigenous child's view of the current situation of the land regularization process of the Kaiowá and Guarani in the state of Mato Grosso do Sul (resumed Pakurity), Brazil. Among the reports for the research the indigenous leader made a point of having his time in the Krenak Indigenous Reformatory, Minas Gerais, recorded. Based on this request, we chose, as the goal of this work, to present one of several histories lived by the natives during the military dictatorship.

\footnotetext{
${ }^{1}$ Frase dita por Bonifácio Reginaldo Duarte, líder indígena da aldeia Pakurity, em Dourados (MS), durante a pesquisa e registrado no caderno de campo em 6 de fevereiro de 2016.

2 Graduado em: Filosofia/UNISAL; Pedagogia/UNIC. Especialização em Antropologia; Mestrado em Educação Indígena/UFMT; Doutorado em Antropologia/USAL e Pós-doutorado/UNTREF. Representa a ABA na CNEEI. Professor Adjunto da UFMS, da Pós-graduação em Antropologia Social e da Pósgraduação em Direitos Humanos (FADIR/UFMS). Bolsista Produtividade (PQ2). E-mail: hilarioaguilera@gmail.com.

${ }^{3}$ Mestra em Antropologia Sociocultural (UFGD). Graduada em Ciências Sociais (UFMS), recebeu o prêmio Claude Lévi-Strauss (pôster/2014) da $29^{\circ}$ Reunião Brasileira de Antropologia com o tema referente as Crianças Kaiowá e Guarani em situação de acampamento na região sul do estado de MS. Atualmente é supervisora da Ação Saberes Indígena na Escola (MEC/SECADI). E-mail: soninhalucas@ gmail.com .
} 
The methodological procedure was fieldwork, through which we obtained participant observation, a field diary and other forms of records. We can say that the reports of the Indians, in particular that of $m r$. Bonifácio, a leader in the reclaiming of the land, bring to light the violence and abuse they suffered, in the form of illegal prisons, physical violence, forced labor and even removal, whether forced or under duress, from their traditional lands. Keeping the memory of one of the many cases of Indians imprisoned in the Krenak is a way of not allowing the Brazilian State to forget the violence it has practiced, still to be repaired.

KEYWORDS: violence; dictatorship; Krenak Reformatory; territory; indigenous rights.

\section{Introdução}

A história aqui abordada sobre uma parte da vida do indígena Bonifácio Reginaldo Duarte, líder da aldeia Pakurity, ${ }^{4}$ durante sua permanência no Reformatório Agrícola Indígena Krenak (MG), apareceu durante a realização do trabalho de campo para cumprir os requisitos da conclusão do mestrado em Antropologia Sociocultural (LUCAS, 2017), estudo realizado a partir do olhar da criança indígena da aldeia Pakurity sobre a atual situação do processo de regularização fundiária dos Kaiowá e Guarani no estado de Mato Grosso do Sul. Durante este processo de pesquisa, a indagação foi: abordar ou não o tema "Krenak" em uma dissertação sobre crianças indígenas? Em vários encontros com o líder Bonifácio uma das vertentes abordada foi o tempo em que passou pelo presídio Krenak. Em todas as conversas que tivemos, e ao sentar para ouvi-lo, o tema referido sempre aparecia. Segundo ele "quero deixar esta história viva. Não é lenda. Eu sou prisioneiro do Krenak". Diante de tantas conversas e diálogos, decidimos registrar a permanência e a passagem desse líder indígena por aquela que, segundo ele, foi a parte de "minha vida mais pesada". Ou seja, a permanência no reformatório Krenak foi a circunstância mais difícil, sofrida e complicada de sua vida até o momento. Admitimos, assim, diante da insistência do narrador, sr.

\footnotetext{
${ }^{4}$ A aldeia Pakurity está localizado no km 17 da BR 463, aproximadamente 20km do perímetro urbano da cidade de Dourados (MS), em direção à Ponta Porã (MS).
} 
Bonifácio, deixar fixado no texto seu relato sobre a prisão Krenak, trazendo sua história para conhecimento de outros.

Para Bonifácio, a sua permanência no reformatório Krenak é, antes de mais nada, efeito da realidade em que os indígenas do Mato Grosso do Sul se inserem. Para ele, nos últimos anos, os povos indígenas do estado vivenciam uma realidade de constante conflito fundiário, o qual só é possível ser entendido através da compreensão do processo histórico de colonização e ocupação deste estado, tema já abordado academicamente por vários autores ${ }^{5}$. Entre tantos fatos históricos, desde os tempos em que os indígenas podiam viver livremente em seus territórios, passando pelo esparramo e as ações do Estado em concentrar os indígenas em um determinado local com a formação das reservas, até a articulação dos indígenas nas diversas maneiras de rever seus direitos, posse e permanência em seus territórios tradicionais, na segunda metade do século $X X$, assim como a dispersão da parentela para as reservas demarcadas na época, especialmente Jaguapiru (Dourados) e a Tei'ykue (Caarapó), e posteriormente a luta para as retomadas ${ }^{6}$, que desponta a liderança de Bonifácio e acarreta uma relação tensa com os poderes (representantes da Fundação Nacional do Índio - FUNAl e proprietários rurais) da época. Segundo o líder indígena, sua liderança e o desejo de manter os indígenas na aldeia Pakurity - contrapondo-se aos interesses do estado em popular as áreas devolutas, que se somam aos interesses do agronegócio - foram os motivos preponderantes para a sua condução e permanência ao reformatório Krenak.

Não há aqui a pretensão de descrever ou aprofundar o tema da ditadura militar e, tampouco, sobre o Reformatório Agrícola Indígena Krenak (MG), assuntos não centrais à pesquisa dos autores, mas sim de

\footnotetext{
${ }^{5}$ Neste trabalho não temos o objetivo de descrever detalhadamente este processo histórico de colonização e ocupação das terras indígenas no estado do Mato Grosso do Sul. Maiores detalhes podem ser encontrados nas obras dos seguintes autores: Schaden (1974), Brand (1997), Pereira (1999, 2004), Mura (2006), Barbosa da Silva (2007), Cavalcante (2013), entre outros.

${ }^{6}$ Segundo CRESPE (2015.p.136) "as áreas de retomadas são áreas dos antigos sítios de ocupação que passam a ser parcialmente reocupadas pelos índios, daí a noção de retomar algo que, segundo a ótica indígena, lhes pertence".
} 
apresentar a história vivenciada pelo líder indígena Bonifácio Reginaldo Duarte durante a ditadura militar, que sendo de Mato Grosso do Sul, foi enviado ao Reformatório Krenak como forma de punição. Sendo assim, é uma maneira de fazer memória de um dos diversos casos de indígenas presos no Reformatório Krenak e não permitir o esquecimento das violências praticadas pelo Estado brasileiro em relação aos povos indígenas, que devem ser reparadas.

\section{Quem é Bonifácio Reginaldo Duarte}

Bonifácio Reginaldo Duarte (Figura 1), atualmente com 75 anos é da etnia Kaiowá, filho de Pacheco Duarte e Felícia Duarte. Nasceu e viveu na Aldeia Pakurity até seus oitos anos de idade, quando foi forçado a deixar a área para retornar anos depois. Casou-se uma única vez com Priscila de Souza, da etnia Guarani, filha de Daniel Souza e Santa Souza, nascida no dia 3 de agosto de 1950, e tiveram cinco filhos. Conforme o senhor Bonifácio, todos seus descendentes, assim como ele próprio, são nascidos na aldeia Pakurity ${ }^{7}$.

O senhor Bonifácio é um líder indígena de branda aparência e fala mansa e cativa para quem o escuta. Nas visitas a campo, ficamos por horas ouvindo seus contos e suas histórias. Trata-se de uma figura contemporânea de líder kaiowá, sendo chefe de uma grande família, líder político e chefe religioso (tekoaruvicha).

Os estudos de Crespe (2009) e de outros pesquisadores, como Pereira (2004) e Mura (2006) acerca das características de um líder kaiowá e guarani, conformam que estes elementos encontram-se presentes também em Bonifácio, e podem ser descritos como:

\footnotetext{
${ }^{7}$ A aldeia Pakurity está localizado no km 17 da BR 463 a, aproximadamente, $20 \mathrm{~km}$ do perímetro urbano de Dourados em direção à Ponta Porã/MS.
} 
O chefe da família extensa deve ser um sábio, exercendo a liderança pautada na religiosidade adquirindo maior prestígio quando se torna avô. Ele detém o conhecimento de sua cultura, do tipo de comportamento ideal para a reprodução da mesma, ele reza, ensina e organiza. Entretanto, o alcance de sua liderança está, via de regra, circunscrito a sua família extensa, e fica mais evidente em situações de conflitos, ou durante rituais religiosos. Um chefe consegue poderes que extrapolam os limites da família extensa, apenas quando seu poder religioso for reconhecido por outras famílias extensas, se tornando um tekoaruvicha, entretanto, o poder do tekoaruvicha não anula a liderança dos tamõi locais (CRESPE, 2009. p. 34).

\section{Figura 1 - Bonifácio Reginaldo Duarte.}

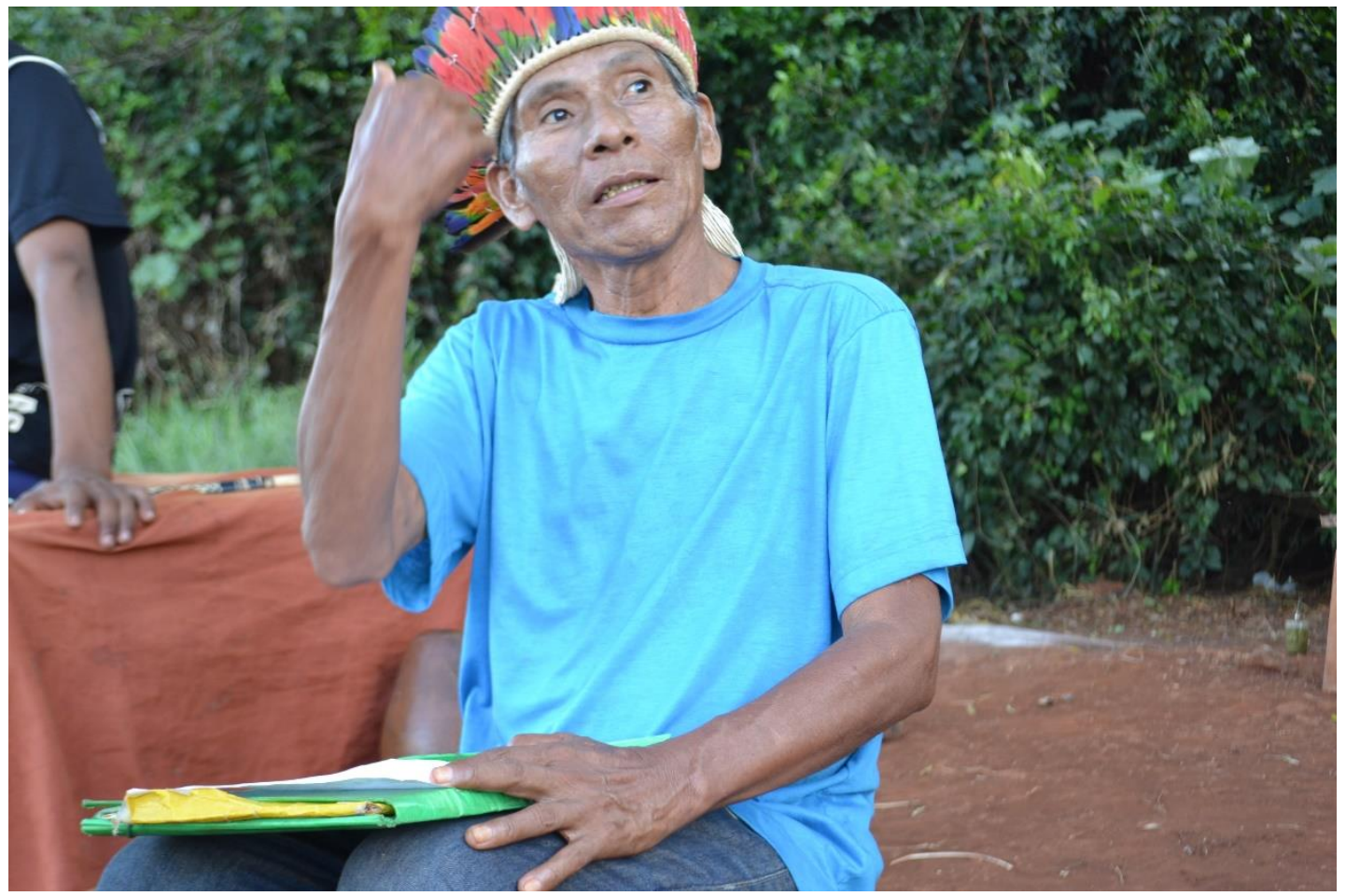

Fonte: Arquivo de pesquisa, Sônia Rocha Lucas, 2016.

No caso do Pakurity, Bonifácio atingiu este nível do tekoaruvicha, ou seja, exerce influência política e religiosa para além do seu grupo macrofamiliar. Podemos, assim, neste caso, acrescentar as palavras de Pereira: 
O hi'u pode ser também denominado de te'yi-ru, cuja tradução literal seria "pai da parentela", remetendo mais uma vez às qualidades já descritas, como ser esta uma pessoa de idade elevada, com vários filhos e netos, com os quais mantém uma relação permanente, baseada na cooperação e na dependência.

Trata-se, portanto, do chefe destituído de poder, contando apenas com a sua capacidade discursiva, seu carisma, bondade e generosidade. O recurso à violência é veemente repudiado pelos membros do $t e^{\prime} y i^{8}$. Pela sua própria natureza, o hi'u dificilmente pensará em exercer a violência contra alguém de seu grupo, sob pena de ver desaparecer repentinamente sua autoridade (PEREIRA, 1999. p. 88).

A figura carismática de Bonifácio é motivo de nucleação ao seu redor, de seus filhos, filhas, netos e agregados, assim como dos demais indígenas do Pakurity, com olhares atentos em quais serão suas palavras e decisões. Palavras que são ditas através de seu jeito calmo e manso, o que demonstra seu status e a grande aceitação dos que o rodeiam.

Bonifácio, em nenhum momento exerce sua autoridade através da violência contra alguém de seu grupo. Podemos demostrar tais características marcantes do líder através da explicação do significado de seu nome: segundo Bonifácio, o seu pai, Pacheco Duarte, o chamava de Iraí $^{9}$, nome baseado em um tipo de mel, o qual o seu pai utilizava a fim de destacar as suas qualidades como uma pessoa doce e que cativa a muitos. Nos relatos Bonifácio, em meio a um largo sorriso, comenta que o nome Iraí, nessa geração, é dado ao seu filho Vailton.

Atualmente Bonifácio é a pessoa mais idosa do grupo que se encontra na retomada Pakurity. É através dele que os mais jovens, bem como toda a comunidade, têm acesso à narrativa dos fatos ocorridos na aldeia. Sendo assim, notamos que é em torno de Bonifácio que a parentela se reúne e se reconhece enquanto grupo diferenciado. Segundo Pereira

\footnotetext{
${ }^{8}$ Te 'yi conforme Pereira (1999.p.85) são unidades de residência que reúnem um número variável de fogos familiares, tema que será abordado no capítulo 3.

9 Segundo a dissertação de Luciane Cheidi Melo Borges (2011,.p. 114) a palavra Irai vem do tupi e significa: Ira = abelha, mel: $Y=$ rio. O rio do Mel, o Rio Doce. Já a espécie de abelha que recebe o nome de Iraí é uma abelha-sem-ferrão da espécie Nannotrigona testaceicornis, bastante comum no Brasil.
} 
(1999, p. 85), o reconhecimento torna este líder o cabeça de parentela. Bonifácio ainda demonstra grande capacidade de se articular com os parentes e é por ele que passam todas as decisões significativas da aldeia Pakurity. Seja a construção de uma nova casa, ou a mudança de um parente de um determinado local da aldeia para outro, ou, ainda, a preparação do solo para uma plantação coletiva. Todas essas decisões são tomadas segundo a orientação de Bonifácio, o que o torna muito visível também para o entorno, fato que tem motivado ameaças de morte e, inclusive, uma tentativa de assassinato nos últimos anos.

Diante do significado de Bonifácio como líder indígena e como protagonista, narrando a história do Pakurity, é importante trazermos os dados referentes à sua parentela, através de um diagrama de parentesco (prática tradicional nos estudos clássicos de antropologia do parentesco) e de uma tabela que representa as relações e o grau de parentesco entre as pessoas da família. $O$ diagrama segue abaixo:

Figura 2 - Diagrama de Parentesco de Bonifácio Reginaldo Duarte



Fonte: Arquivo de pesquisa, Sônia Rocha Lucas, 2016.

Relacionado a parentela de Bonifácio, apresentamos uma tabela que nos fornecerá uma outra maneira de perceber as relações e o grau de parentesco entre cada membro de sua extensa família. 
Tabela 1 - Relação nominal de parentesco de Bonifácio

\begin{tabular}{|c|c|c|c|}
\hline $\mathrm{N}^{*}$ & Nome & $\mathrm{N}^{*}$ & Nome \\
\hline 1 & Priscila de Souza & 19 & Carolaing Femandes \\
\hline 2 & Ustáguis Duarte & 20 & Layinea Fernandes \\
\hline 3 & Paulo Duarte & 21 & Ariane Femandes \\
\hline 4 & Pacheco Duarte & 22 & $\begin{array}{l}\text { Waniely - Năo sabem informar } 0 \\
\text { sobrenome }\end{array}$ \\
\hline 5 & Felicia Duarte & 23 & Evandro Carmona de Souza \\
\hline 6 & Clara Lúcia de Souza Duarte & 24 & Ezequiel Carmona de Souza \\
\hline 7 & João Femandes & 25 & Rafael Carmona de Souza \\
\hline 8 & $\begin{array}{l}\text { Neide - Nấo sabem informar o } \\
\text { gobrenome }\end{array}$ & 26 & Daniel Carmona de Souza \\
\hline 9 & Robson de Souza Duarte & 27 & Everton de Souza Martins \\
\hline 10 & Sidelia Carmona & 28 & Meidiam de Souza Martins \\
\hline 11 & Wailton de Souza Duarte & 29 & Eliagen de Souza Martins \\
\hline 12 & Ester Sarati & 30 & Vanessa Martins Fernandes \\
\hline 13 & Valdir Martins & 31 & Everton Martins de Souza \\
\hline 14 & Dagmar de Souza Duarte & 32 & Diego Martins de Souza \\
\hline 15 & JaniQ Sanches Fermandes & 33 & Ixordi Martins de Souza \\
\hline 16 & Boberlei de Souza Duarte & 34 & Naiemily Maritns de Souza \\
\hline 17 & Claudinéia Fernandes & 35 & $1^{x}$ Filha de Roberlei de Souza Duarte \\
\hline 18 & Ana Lúcia Martins Flores & & \\
\hline
\end{tabular}

Fonte: Arquivo de pesquisa, Sônia Rocha Lucas, 2016.

Segundo a construção do diagrama podemos notar que a família de Bonifácio conta com 5 filhos e 18 netos. A filha mais velha é Clara Lúcia $\left(n^{\circ} 6\right)$, casada com João Fernandes $\left(n^{\circ} 7\right)$, que tiveram quatro filhas. $O$ segundo filho é Robson de Souza Duarte $\left(n^{\circ} 9\right)$. Segundo Bonifácio, Robson é responsável por cuidar do Pakurity em sua ausência. Foi casado com Neide ( $\left.{ }^{\circ} 8\right)$, e dessa união tiveram uma filha por nome Vaniely. Atualmente está com Sidélia $\left(n^{\circ} 10\right)$, com quem tem quatro filhos. Vailton ( $\left.{ }^{\circ} 11\right)$, também chamado de Iraí, é o terceiro filho de Bonifácio. É casado com Ester $\left(n^{0} 12\right)$ e juntos têm três filhos. Dagmar $\left(n^{0} 14\right)$, a quarta filha, foi casada pela primeira vez com Valdir ( $\left.n^{\circ} 13\right)$, com quem teve uma filha e três filhos. Depois disso, passou por uma separação e casou-se, pela segunda vez, com Jairo ( $\left.n^{\circ} 15\right)$, e juntos tiveram Naiemily Maritns de 
Souza ( $\left.n^{\circ} 34\right)$; Jairo posteriormente faleceu e novamente Dagmar casouse com Valdir - tiveram mais um filho com o nome de Ivordi ( $\left.n^{\circ} 33\right)$. 0 último filho da união de Bonifácio e Pricila é Roberlei de Souza Duarte ( ${ }^{\circ}$ 16), casado com Claudinéia Fernandes ( $\left.n^{\circ} 17\right)$, com quem tem uma única filha.

Esta qualidade de liderança de Bonifácio torna-o o centro de conhecimento e de decisões em toda a aldeia, não somente para seus parentes consanguíneos, mas para os agregados, parceiros políticos e religiosos. Nosso personagem julga que herdou este seu comportamento de líder de seu pai e, segundo relatos, desde muito jovem Bonifácio já construía seu status de ser um grande líder, o que certamente incomodava os agentes - chefes de posto - da FUNAI, os quais representavam nas aldeias o órgão indigenista, por sua vez comandado por representantes do exército.

\section{O reformatório agrícola indígena Krenak}

O presídio ou Reformatório Agrícola Indígena Krenak encontrava-se no município de Resplendor (MG) e teve o início de suas atividades no ano de 1969, no local do antigo Posto Indígena Guido Marlière. O referido centro reformatório estava sob o comando da Polícia Militar mineira, função essa recebida pela recém-criada Fundação Nacional do índio (Funai), que deveria gerir as terras indígenas do estado de Minas Gerais (REZENDE, 2015. p.506).

José Gabriel Silveira Corrêa (2000), descreve sua pesquisa de mestrado como uma incursão acerca da história do Reformatório Agrícola Indígena Krenak, uma instituição destinada a recuperar os índios denominados "criminosos". Cabe desde o início a pergunta: qual seria a tipificação de "criminoso" para o regime da época? O foco principal da pesquisa de Corrêa (2000) é trazer o Reformatório, e mais especificamente as práticas punitivas, interligados com a prática tutelar 
dos órgãos competentes pelo estado, em (des)favor dos índios (2000, p. 98).

O termo Krenak, conforme Corrêa, foi usado para denominar o Reformatório da seguinte maneira:

Os Krenak, segundo a bibliografia, seriam um dos grupos de índios Botocudos que viviam na região do rio Doce em Minas Gerais e Espirito Santo. A denominação Krenak é derivada de um dos grupos contatados pelos funcionários do SPI no início do século - que era chefiado pelo capitão Krenak -, e que com os anos "passa" a ser atribuída, provavelmente pelos funcionários do SPI, aos diversos grupos que se fixam ou são fixados pelo SPI no PIGM (2000, p. 100-101).

O Reformatório Agrário Indígena Krenak foi instalado dentro da área de 3.983 hectares do Posto Indígena Guido Marlière, criado no início do século às margens do rio Doce e "também conhecido ou denominado como presidio, reformatório, centro de reeducação, colônia correcional ou mesmo posto indígena" (CORRÊA, 2000, p. 128), o qual, segundo dados, operou no curto período entre o início de 1969 e o final de 1972. Segundo o autor:

O reformatório - apesar de descrito como operando a partir do final de 1969 ou do ano de 1970 - começa a receber índios qualificados como delinquentes a partir de fevereiro, mais precisamente no dia 24 de janeiro de 1969, quando chegou à área do antigo Posto Indígena Guido Marlière, para ser reeducado, o índio Antonio Karajá, removido para lá por ter cometido crime de homicídio em sua aldeia de origem (MF 306/012/1079). A partir desta data e até o final do ano de 1972, o Posto receberia uma leva considerável de índios enviados para o mesmo, e acusados de diversos "crimes" (CORRÊA, 2000, p. 128-129).

O Reformatório Krenak tinha como objetivo principal "reeducar, atrair e pacificar" índios delinquentes. Esta ideia não era compartilhada por Queiroz. Para o autor, para além de um reformatório, Krenak "funcionou como verdadeira prisão", ou seja, como um verdadeiro presidio para índios durante o regime militar, pois os indígenas cumpriam 
todos os tipos de penas comuns em qualquer penitenciária. O autor ainda acrescenta que os indígenas eram "reclusos em celas comunais ou individuais, submetidos a trabalhos forçados e muitos deles torturados como forma de espalhar o terror para se garantir a obediência e a disciplina" (QUEIROZ apud CORRÊA, 2000, p. 94).

Levando em consideração o Reformatório Krenak como um presidio para "reeducar", Corrêa (2000, p. 155) lista os principais motivos que levavam os indígenas à prisão.

Tabela 2 - Lista de motivos para o envio ao reformatório entre os anos de 1969 e 1972

\begin{tabular}{|c|c|c|c|c|}
\hline MOTIVO & $\begin{array}{c}\text { Índio } \\
\text { Confinado }\end{array}$ & $\begin{array}{c}\text { Guarda } \\
\text { Rural } \\
\text { Indigena }\end{array}$ & $\begin{array}{c}\text { Etnia } \\
\text { Krenak }\end{array}$ & Total \\
\hline Agressão a mulher & & 1 & 1 & 2 \\
\hline Atritos com o chefe do Posto Indigena & 4 & & 1 & 5 \\
\hline Embriaguez & 18 & 3 & 9 & 30 \\
\hline Embriaguez e homicidio & 1 & & & 1 \\
\hline Homicídio & 15 & & & 15 \\
\hline Problema mental & 1 & & & 1 \\
\hline Prostituição & 1 & & & 1 \\
\hline Relações sexuais & 2 & & 2 & 4 \\
\hline Roubo & 12 & & & 12 \\
\hline Roubo e embriaguez & & 1 & & 1 \\
\hline Roubo e Pederastia & 1 & & & 1 \\
\hline Saida sem autorização & & & 3 & 3 \\
\hline Sem motivo para o envio & 9 & 13 & 1 & 23 \\
\hline Vadiagem & 5 & & & 5 \\
\hline Vadiagem e embriaguez & 1 & & & 1 \\
\hline Vadiagem e uso de drogas & 1 & & & 1 \\
\hline TOTAL & 71 & 18 & 17 & 106 \\
\hline
\end{tabular}

Fonte: Corrêa (2000, p. 155)

Na tabela acima podemos perceber que o motivo com maior quantitativo para ser recolhido ao Reformatório é o de "embriaguez", seguido por "Sem motivo para o envio". Foram diversas as razões para o 
recolhimento dos indígenas, mas o que nos impressiona são os casos "sem motivo".

Certamente que o item "atritos com o chefe de Posto Indígena" e os "sem motivo para envio" congregam todos aqueles que, de alguma maneira, resistiam às políticas de assimilação, desterritorialização (perdas territoriais) e confinamento em exíguos espaços de reservas.

Com esta breve abordagem para contextualizar o Reformatório Agrícola Indígena Krenak, podemos ter um pano de fundo para acompanharmos a história narrada por Bonifácio Reginaldo Duarte, o qual afirma ter passado três anos e quatro meses retido neste Reformatório em Minas Gerias.

Esta narrativa do senhor Bonifácio se insere em uma dissertação de mestrado em Antropologia Sociocultural (LUCAS, 2017), a qual teve como tema "Crianças Indígenas no Acampamento Pakurity - MS: quem são, como vivem e como percebem a situação de moradias móveis", visando apresentar um estudo sobre o olhar da criança indígena da atual situação do processo de regularização fundiária dos Kaiowá e Guarani no estado de Mato Grosso do Sul, enfocando especificamente o acampamento Pakurity, bem como identificar e descrever quem são os Kaiowá e Guarani que vivem nesta aldeia e sua relação com a rede de parentela, dando maior ênfase para as crianças indígenas. Tendo como tema central a criança indígena e sua infância, por que abordar o tema "Krenak"? Essa foi uma indagação que nos acompanhou durante muito tempo: colocar ou não esse tema nos escritos da pesquisa. Durante todo o trabalho de campo, um dos assuntos abordados pelo sr. Bonifácio foi o tempo em que passou pelo reformatório Krenak. Em todas as conversas com ele, durante o trabalho de campo, o tema referido sempre vinha à tona, sempre acrescentando mais algum detalhe. Segundo ele "quero deixar esta história viva. Não é lenda. Eu sou prisioneiro do Krenak".

Para Bonifácio o lugar nunca fora uma forma de "reformatório" e sim um presidio. Em nenhuma das conversas ele utiliza o termo "reformatório", mas faz questão de enfatizar que sobreviveu a um 
"presídio", e com práticas desumanas. Diante de tantas conversas e diálogos, decidimos registrar a permanência e a passagem desse líder indígena, segundo ele, pela parte de "minha vida mais pesada", mostrando, assim, que foi a circunstância de sua vida mais difícil e complicada até o momento. Admitimos aqui, a insistência do narrador, senhor Bonifácio, em deixar fixado no texto seu relato sobre a prisão Krenak, algo inicialmente fora dos planos da pesquisa.

Para isso, iniciaremos com a abordagem de quem é este líder indígena e, em seguida, a experiência vivenciada no Reformatório Krenak, e narrada por ele.

\section{Sobrevivente do Krenak}

Para Bonifácio a história vivenciada no presídio começou quando estava com 26 ou 27 anos. Segundo ele, o momento em que antecedeu sua ida ao reformatório foi:

Eu já estava com 27 ou 26 anos quando me buscaram e me deixaram sentado onde, naquela época, era uma casa de madeira e que hoje é um consultório de dentista, próximo a um pé de taquara. Ali fiquei sentado até o anoitecer. Quando trouxeram mais dois indígenas, o Calair e um tal de Leopoldo. Éramos nós três. Somente à meia noite chegou o carro do soldado e nos colocou os três lá dentro, sem falar nada. E fomos, sem saber para onde (Entrevista, 06/02/2016).

$\mathrm{Na}$ viagem de ida, de acordo com a marcação de tempo feita por Bonifácio, passaram na estrada o dia todo, incluindo o "meio dia e o entardecer", chegando no local apenas "à noitezinha", mostrando, assim, que o local referido era distante de onde se encontrava. Uma distância aproximada de $1.850 \mathrm{~km}$, percorrida, segundo a narrativa, em dois dias e duas noites. 
A primeira impressão do local, narrada pelo líder indígena, é uma mistura de alegria e estranhamento. Alegria por ver muitos outros indígenas agrupados e estranhamento porque todos estavam calados. Segue seu relato:

Quando chegamos lá havia um tronco muito grande em que passávamos no meio dele. Passando esse tronco já se via os índios. Fiquei um pouco alegre, mas achei um pouco diferente, pois ninguém falava nada. Tinha uns índios amarrados pelo pé, de braços amarrados com uma corda comprida, assim... amarrados de cabeça pra baixo. E aí a gente olhava. Tinha alguns índios também em celas. $E$ tinha índios mortos. E ficamos lá (Bonifácio Reginaldo Duarte, 06/02/2016).

Ao chegar no local, Bonifácio não o identificou de imediato. Somente no dia seguinte começou a descobrir do que se tratava, o que realmente era aquele lugar, ao conversar com um outro indígena da etnia mbya (guarani). Ele narra: "meio dia escutei uma voz falando em guarani, era de índios guarani mbya. Eles se aproximaram falando em guarani e perguntei o que era aquele lugar. Eles responderam que aquilo era um presídio". Foi através da língua materna falada (língua guarani) dos que ali já se encontravam, que Bonifácio identificou as várias etnias encontradas no presídio. Segundo sua narrativa, ele pôde identificar indígenas das etnias: guarani mbya, krahô kanela, charruá e os da etnia krenak. Segundo alguns que lá estavam, esses últimos eram tidos como uma espécie de policiais, "eram uns índios cabeludos, fortes, grandes, altos", e ajudavam os funcionários "brancos" do presídio.

O três indígenas, Calair, Leopoldo e Bonifácio, que foram levados do então sul de Mato Grosso, não permaneceram juntos. Enquanto Bonifácio ficou no lugar narrado, os outros dois foram levados para um outro lugar, que ele chama de "Ilha das Cobras". Ao ser questionado sobre o porquê do nome, o líder indígena reponde:

Leopoldo e o Calair foram para a ilha das cobras. Jogaram ele no meio da água para os bichos comerem 
ele lá, mas ele voltou por causa do $m y m b y^{10}$ e a cobra não chegava perto dele para pegar ele. E quando o soldado foi olhá-lo ele ainda estava vivo. Então decidiram levá-lo de volta. Levou para o Krenak. Por isso que o mymby é muito importante, a cobra respeita ele. Ele conta aos outros que iam junto lá, a cobra vinha e pegava mesmo e levava (Bonifácio Reginaldo Duarte, 06/02/ 2016).

Pode-se perceber que o lugar recebe o nome devido à tortura: os indígenas eram lançados em um lago repleto de cobras com a finalidade de não retornarem. Segundo o senhor Bonifácio, eram raros os que conseguiam voltar daquele lugar com vida.

Enquanto permaneciam no reformatório, todos os dias os indígenas realizavam trabalhos forçados. A atividade realizada por Bonifácio baseava-se em "fazer destocada", ou seja, arrancar os tocos que ficavam no terreno após o abatimento das árvores. Era exigido que tal atividade não causasse grandes transformações no solo; era preciso não "mexer na terra". Nessa atividade Bonifácio contava com a ajuda de um facão.

Quanto aos afazeres, normalmente era estipulado uma quantidade de trabalho diário. Caso não fosse atingido, o indígena poderia sofrer algum tipo de pena ou sanção, que poderia ser desde de trabalhar mais horas no dia seguinte _a ir direto para o tronco, local público de tortura. Sobre isso Bonifácio diz:

Essa aí foi minha vida mais pesada. Era assim aquela
época. E aí vieram vários tipos de pena, que eles falam.
Eles davam a pena mais pesada, cabeça para baixo.
Passávamos fome direto lá (Bonifácio Reginaldo Duarte,
$06 / 02 / 2016)$.

A respeito dos trabalhos forçados e das práticas de tortura levadas a cabo no regime militar, no presídio Krenak, temos o seguinte:

O Estado brasileiro criou, no final dos anos 1960, uma cadeia oficial em território Krenak, exclusiva para a detenção de indígenas, sobre a qual colhemos denúncias

\footnotetext{
${ }^{10}$ Mymby, segundo Bonifácio, é uma espécie de instrumento musical (flauta) que ao produzir seu som traz consigo um efeito mágico para repelir as cobras.
} 
de casos de morte por tortura no tronco, trabalho forçado e desaparecimento de prisioneiros. É recomendável a continuidade da investigação - tanto sobre as cadeias para índios, como sobre a Guarda Rural Indígena -, que não se esgota com esse trabalho (KEHL, 2014. p. 233).

A autora ainda acrescenta a realidade da Guarda Rural Indígena, a qual, segundo Bonifácio, era quase toda composta por indígenas da etnia Krenak, cooptados para ajudarem nas atividades de repressão e contenção dos presos durante este período.

No caso do nosso interlocutor, ao ser indagado se sofreu alguma pena no tronco, Bonifácio responde com toda naturalidade: "todo os dias". A pena de ir ao tronco poderia ser empregada por qualquer motivo. Para Bonifácio era o "jogo" que o levava mais vezes ao tronco. Conta que quem tinha o poder de enviar ou não os indígenas ao tronco "era julgo dele", ou seja, era de competência dos "coronéis"1".

O jogo consistia em aguentar o maior número de castigo físico sem chorar. O indígena que conseguia suportar a maior quantidade desses castigos marcava ponto para o "coronel" que, por várias vezes apostou nele, em Bonifácio. Continuando a narrativa, diz:

Quem ia pro tronco do coronel. E nesse tronco ficávamos amarrado lá. E quem aguentava reiada mais forte, mais reiada pra não chorar e sentir dor. É difícil aguentar a dois ou três reiadas sem chorar, mais guarani mbya aguentava. Levavam cada reiada, dez reiada era isso aí. O pessoal, o coronel gostava deles porque ganhavam pontos (Bonifácio Reginaldo Duarte, 06/02/ 2016).

Bonifácio ainda conta sobre a estratégia dos indígenas guarani mbya para suportarem o castigo físico, conforme narrado a seguir:

Aí um dia perguntei para um guarani mbya: como você aguentou? Ele falou erandutai. Erandutai é uma madeira que dava no mato e que passa tudo no corpo e é igual anestesia. Então passava o sumo da erva, por isso ele aguentava essa pancada. Aí eu comecei a passar isso também no corpo. E aí quando ia pro tronco aguentava

\footnotetext{
${ }^{11}$ Coronéis, termo utilizado pelo líder indígena para se referir a mais alta hierarquia do local.
} 
dez, nove, dez... (Bonifácio Reginaldo Duarte, 06/02/ 2016).

Diante desse quadro de tortura e sofrimento, era corriqueira a morte de inúmeros indígenas que não resistiam às práticas contínuas e aos ferimentos. Para Bonifácio os indígenas que não resistiam ao presídio eram os Guarani Mbya, "chegavam em duplas e morriam lá mesmo" e eles davam fim aos corpos lá mesmo. Bonifácio narra que no local havia um "carrinho grande" no qual transportavam os cadáveres até "um buraco em que colocavam os corpos" $(06 / 02 / 2016)^{12}$. Bonifácio continua sua narrativa e afirma que outras etnias também não resistiam às torturas. Diz que os Charruá, quando chegavam, nem eram fichados e seguiam direto para a tortura. Eles eram degolados no momento que chegavam no Krenak. Quanto à etnia dos Krahô Kanela afirma que os indígenas conseguiam resistir até, no máximo, seis dias no reformatório - "eles eram torturados frente à frente, face à face", onde todos podiam ver. Toda essa tortura, segundo Bonifácio, era realizada pelos próprios indígenas da etnia Krenak em cumprimento às ordens do "generais", pois se não o fizessem, eles eram punidos e também podiam ir parar no tronco.

Além das torturas físicas, outra forma de punição era através da alimentação. A comida era distribuída apenas uma vez ao dia, ou seja, insuficiente para manter homens saudáveis trabalhando na roça. Segundo Bonifácio, sua resistência diante da falta de comida no reformatório só foi possível através do uso do $\operatorname{cará}^{13}$ e da tanajura. Bonifácio conta que "ponhava no porunga"14 (Figura 3) esse cará, socava e, juntamente com a tanajura, a qual após passarem no fogo, levavam para o "mato", referindose aos momentos em que eram conduzidos aos trabalhos forçados, anteriormente abordado nesse texto. Com esses alimentos tradicionais e

\footnotetext{
12 Caderno de Campo: Bonifácio Reginaldo Duarte no dia 6 de fevereiro de 2016;

${ }^{13}$ Cará é um tubérculo cultivável pertencente a várias espécies da família das dioscoreáceas.

${ }^{14}$ Porunga é um fruto não comestível, caracterizado por seu tamanho grande, formado por uma casca grossa e com sementes por dentro, sem polpa. Utilizado para confecção de objetos e utensílios de uso dos indígenas.
} 
"alternativos", ele e seus amigos conseguiam resistir à fome e ao sofrimento.

\section{Figura 3 - Bonifácio e uma porunga (cabaça)}

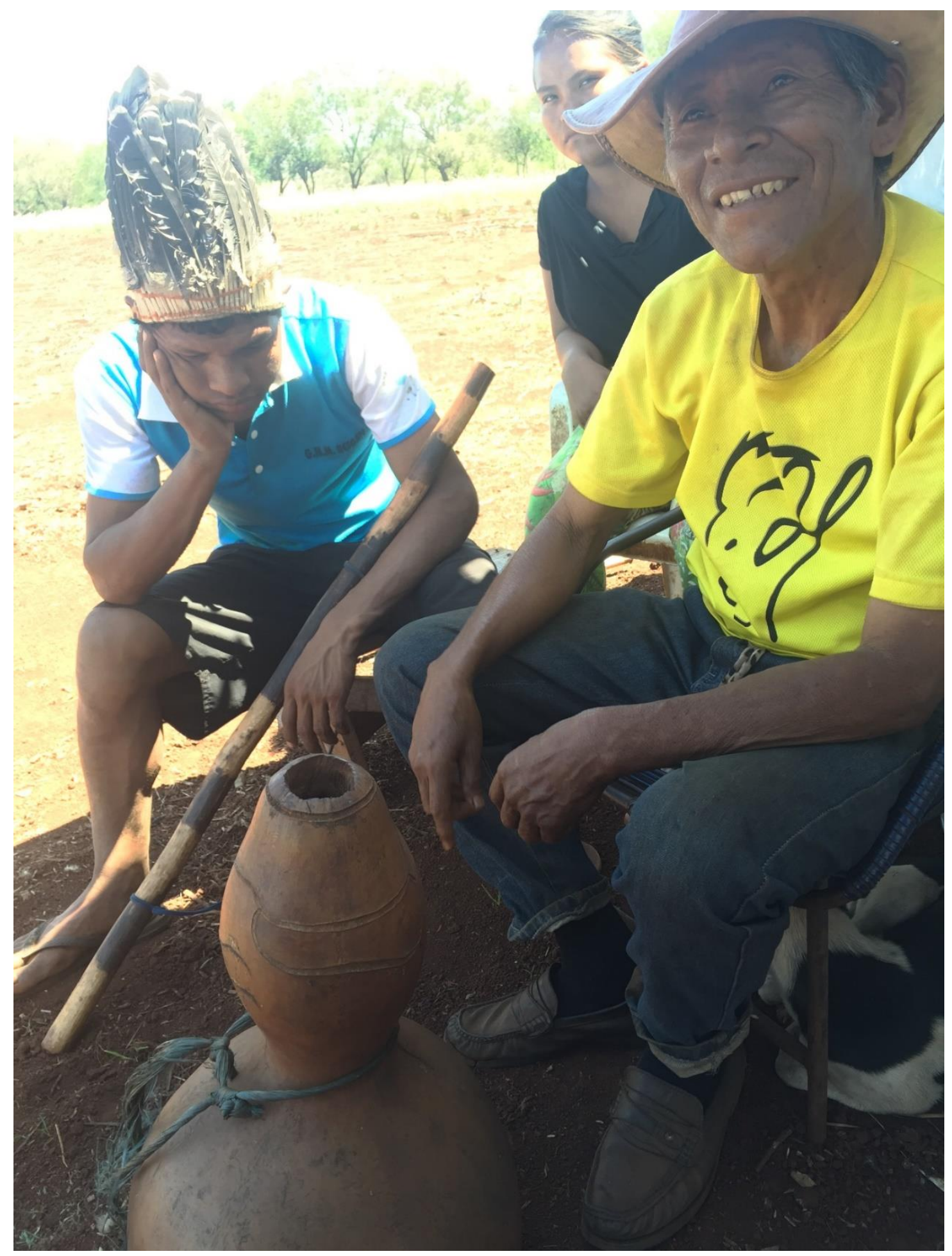

Fonte: Arquivo de pesquisa, Sônia Rocha Lucas, 2016. 
Foram 3 anos e 4 meses que Bonifácio permaneceu no Reformatório Agrícola Indígena Krenak. Quanto ao seu retorno, Bonifácio diz, "eu voltei por acaso em um dia". Juntamente com Calair e Leopoldo, retornaram escoltados por um soldado chamado Vanildo. Narra que tal soldado chegou no presídio com um novo grupo de indígenas e ao retornar, levouos consigo.

Bonifácio também relatou o desaparecimento de parentes. Diz:

Aí depois que eu vim pra cá, levou meus irmãos. O Eustáquio Duarte e o Paulo Duarte. Aí que foi junto um tal de Justino e Anita. Justino voltou e a mulher dele não voltou. Meus dois irmãos também não voltaram. De certo ele também pegava pena mais forte. Me falaram que estavam para Chapadão do Sul. Uma vez procurei por dois anos e não achei mais, nem notícia. Decerto que faleceu. Ele pegou outro tipo de pena. Decerto ficou de cabeça pra baixo (Bonifácio Reginaldo Duarte, 16/04/2016).

Fatos semelhantes foram narrados por Valente $(2017$, p. 82$)$ em seu livro "Os Fuzis e as Flechas", que trata da relação do Estado brasileiro com os povos indígenas no período da ditadura militar. Conforme Valente, uma investigação da antropóloga Maria Hilda realizada na Bahia no ano de 1976 releva diversas prisões de indígenas ordenadas pela própria FUNAI. Salienta o caso de Dedé, que fora enviado para o mesmo Reformatório Krenak de Bonifácio em Minas Geris, o qual teve seu fim semelhante aos irmãos de Bonifácio. "Dedé desapareceu durante sua prisão no Krenak" escreveu Maria Hilda em seu relatório enviado à Funai em Brasília (VALENTE, 2017, p. 82). Ninguém nunca mais o viu.

Ao ser questionado se já fez alguma tentativa de encontrar os irmãos, responde que seu amigo Teodoro ao ser enviado para a "ilha das cobras", retornou e não encontrou mais nenhum deles. Diz que "voltou e não viu mais ele, não viu mais ele por lá. Não estava mais. E não podia perguntar também". Esse comportamento de não se fazer perguntas ou questionar o que quer que fosse, era um hábito obrigatório. Quando a 
regra era quebrada ou infringida, o indígena sofria algum tipo de pena, podendo até ir para o tronco. Bonifácio relembra que "não podia perguntar nada. Tinha que ficar quieto, olhar, ver o que ver", e calar.

Toda esta narrativa do sr. Bonifácio repassada durante o trabalho de campo também pode ser encontrada nos arquivos da Comissão Nacional da Verdade (CNV). Em novembro de 2012 foi criado um grupo de trabalho a fim de investigar violações de direitos humanos sofridas por índios e camponeses. Maria Rita Kehl (2014) foi responsável pelo grupo de trabalho que tratou das violações de direitos contra os índios.

Em Mato Grosso do Sul houve três audiências do grupo de trabalho, a fim de verificar relatos sobre a expulsão dos indígenas de suas terras tradicionais. As duas primeiras foram realizadas na Universidade Federal da Grande Dourados, com o intuito de coletar depoimentos sobre a violação de direitos dos indígenas, e contaram com o testemunho de Bonifácio. Cabe ressaltar que o depoimento dele consta no Relatório Final da Comissão Nacional da Verdade (capítulo Indígena - Volume II, 2012).

Maria Rita Kehl, no texto Violação de Direitos Humanos dos Povos Indígenas relata o encontro com Bonifácio Reginaldo Duarte ${ }^{15}$. Segundo ela:

A CNV ouviu, durante a segunda audiência realizada no Mato Grosso do Sul, o depoimento de Bonifácio R. Duarte, índio guarani-kaiowá, também detido no Krenak. Seu relato vai ao encontro das denúncias feitas acima por Antonio Cotrim e produzidas ainda sob a censura dos anos 1970. Emocionado, Bonifácio nos contou, mais de 40 anos depois, suas memórias do tempo da prisão (2014, p. 238).

Podemos dizer que os relatos dos indígenas fornecidos para 0 grupo de trabalho da Comissão Nacional da Verdade trazem à luz as violências sofridas por eles, ou seja, os abusos em prisões ilegais,

15 Para ver a íntegra do depoimento, acesse em 01:23:00 o registro feito pelo MPF: https://www.youtube.com/watch?v=Lyd4oixA-

IU\&index=2\&list=PL9nOMOIx|2jdV9wUHmakajgf1DSS6O-RN . 
violências físicas, trabalhos forçados, estupros e até a remoção forçada ou sob coação e esbulho de suas terras tradicionais, foco principal deste trabalho. Sendo assim, "a memória sobre o desaparecimento de presos no Krenak expõe violências praticadas pelo Estado brasileiro que devem ser reparadas" (KEHL, 2014. p. 239).

Segundo relatos atuais, oferecidos por reportagem da revista Carta Capital (2013), é possível constatar que a sede do reformatório Krenak possuía duas edificações: uma para a administração, almoxarifado e alojamento dos guardas; e outra para o reformatório propriamente dito, com cozinha/refeitório, além de celas individuais, dois confinamentos coletivos e dois cubículos para detenção. Segundo Bonifácio, os prisioneiros frequentemente ficavam encarcerados nestes últimos quando cometiam qualquer tipo de falta mais grave.

"Íamos até um brejo, com água até o joelho, plantar arroz", revela Diógenes Ferreira dos Santos, índio pataxó levado ao Krenak em 1969. "Botavam a gente para arrancar mato, no meio das cobras, e os guardas ficavam em roda vigiando, todos armados", complementa João Batista de Oliveira, conhecido como João Bugre, da etnia Krenak (CARTA CAPITAL, 2013). Vemos que alguns relatos confirmam o que foi dito pelo senhor Bonifácio.

Segundo os registros oficiais levantados pela reportagem da Carta Capital (2013):

Alguns índios permaneceram por mais de três anos e havia indivíduos sobre os quais desconhecia-se até o suposto delito. "Não sabemos a causa real que motivou o seu encaminhamento, uma vez que não recebemos o relatório de origem", escreve o cabo Vicente, ao escritório central da Ajudância Minas-Bahia da Funai, a respeito de um xavante, considerado de bom comportamento, que lá estava há mais de cinco meses (n.p.).

Além de tudo o que foi narrado por Bonifácio, de sua experiência no Krenak de surras com chicotes e o confinamento em solitária, havia ainda a proibição de se comunicar em língua indígena. "Você era 
repreendido, pois os guardas achavam que a gente estava falando deles", lembra. Situação ainda mais difícil para aqueles que não sabiam português. "Tinha que aprender na marra. Ou falava, ou apanhava" (índio João Bugre, narrado na CARTA CAPITAL, 2013, n.p.).

No contexto desses depoimentos para a Comissão Nacional da Verdade, além do reconhecimento de que esses indígenas foram presos políticos, vem também a necessidade da reparação, inclusive porque muitos deles, como certamente foi o caso do senhor Bonifácio, foram presos devido às disputas por suas terras tradicionais.

\section{Considerações finais}

Talvez possamos questionar o motivo de Bonifácio ter sido enviado ao Reformatório Agrícola Indígena Krenak. Talvez a resposta esteja nas suas origens: vindo de família de caciques (líderes), Bonifácio passa a assumir a liderança da comunidade, o que é uma de suas características marcantes até o presente momento; sendo assim, o lugar em que permanecia consequentemente era acompanhado por vários indígenas Kaiowá e Guarani, que se aglomeravam junto a ele, sua família extensa e aliados políticos e religiosos. Para o líder indígena isso era "motivo e uma forma de atrapalhar a dura realidade (de esbulho) em que estávamos enfrentando e, também, os interesses pessoais da família ruralista que ocupou as terras indígenas". Segundo o sr. Bonifácio:

Ao meu ver, acharam por bem me levarem para Minas Gerais em um presídio indígena chamado Krenak. Fui para o Krenak e lá permaneci por 3 anos e 4 meses. Ali presenciei muitas ações bárbaras em um lugar extremamente triste, entre tantos, o mais triste era ver os indígenas chegarem e lá mesmo morrerem e serem enterrados. Depois deste tempo eu voltei para o meu tekoha Pakurity e permaneço até hoje (Bonifácio Reginaldo Duarte, 16/04/ 2016). 
Assim, reafirmamos o fato de que as lideranças indígenas eram enviadas ao Reformatório Krenak para não atrapalharem o confisco de suas terras pelos novos colonos e, assim, liberar estas terras para a colonização e propiciarem o chamado progresso do território nacional, conforme a ideologia da época.

Corrêa (2000) também aborda o fato destas prisões dos indígenas terem por motivação a disputa por suas terras. O autor diz:

Para entender a criação do Reformatório não basta filiálo a uma ampla política de repressão - passível de denuncia pela dimensão nada pacífica que a relação de tutela carrega, mas que pelo próprio das "acusações" se esvazia criticamente -, ou às gestões pessoais de um indivíduo, à perseguição aos índios para obter suas terras ou ao momento de exceção vivido no país. Estas práticas são fundamentais para entender como e porque o reformatório se desenvolveu, mas pode-se perceber também que estas também remetem a um trabalho morto, que apesar de remontar ao início da colonização e às práticas de punição para os índio, tem grande parte de seu desenvolvimento dentro da instituição estatal que antecedeu a Funai (CORRÊA, 2000, p. 98).

Reiteramos, dessa forma, que as prisões feitas no Reformatório Krenak também serviam para remover os indígenas que atrapalhassem o desenvolvimento econômico de algumas regiões do Brasil, como o caso do sul de Mato Grosso no final dos anos de 1960. Mais uma ação do Estado para possibilitar que as terras tradicionalmente ocupadas pelos indígenas (neste caso, os Kaiowá e Guarani), fossem transferidas para os novos colonizadores, autores do propalado desenvolvimento e progresso da União.

Nesse sentido, Valente (2017, p. 78) atesta que "documentos guardados nos arquivos da FUNAI confirmam que as prisões Krenak e Guarani também foram usadas para prender índios que reivindicavam posse de terras e incomodavam a ditadura ou os fazendeiros". O autor ainda narra o estudo de um caso acompanhado pela antropóloga Maria Hilda. O pataxó Samado era um indígena que vivia com sua família na 
área do posto indígena Caramuru, no sul da Bahia, desde o ano de 1920. Em 1947, as terras de Samado foram invadidas, obrigando assim, ele e sua família a abandonarem o local. A reintegração de posse veio por ordem do Ministério da Agricultura e no ano de 1950 o índio Samado retorna à sua terra e a encontra ocupada. No ano de 1967 há a denúncia, junto ao Departamento de Assistência da Funai, de que suas terras ainda continuavam invadidas e que continuavam sofrendo "ameaças e pressões" pelos invasores de terra. Ação que se repetiria dois anos mais tarde, em 1969. E o que se sucedeu foi:

Em 1969, Samado foi preso no Crenak [Krenak] devido a sua persistência em lutar para permanecer na região do "Toucinho". Após libertado, foi jogado para uma gleba de 16,6 hectares conhecida como "Panelão". Ainda sofreu séria oposição ao direito de permanecer na área, já que a terra teria sido negociada arbitrariamente (VALENTE, 2017, p. 80-81).

Somados às histórias de Bonifácio e Samado, certamente há diversos outros indígenas que foram retirados de seus territórios e retidos no Reformatório Agrícola Indígena por conta da luta por suas terras. Trazer a história narrada pelo líder indígena Bonifácio Reginaldo Duarte é trazer sua voz, entre muitas silenciadas, para requerer não apenas o direito à lembrança, mas a retratação das violências praticadas pelo Estado brasileiro.

Entre tantos fatos que ocorreram na história dos povos indígenas no Brasil, este tem sido mais um dos que colaborou para que fossem retirados, expulsos e confinados em pequenas reservas e, muitas vezes, longe de seus territórios tradicionais. É mais um dos episódios de violação dos direitos destes povos originários.

Uso as palavras do Cimi, narradas por Valente que dizem:

A frente principal onde se trava uma luta pela sobrevivência dos povos indígenas não está nos gabinetes dos órgãos oficiais de proteção ao índio ou nas universidades, está na batalha diária por cada palmo de terra, disputada pelos grupos indígenas aos invasores, 
grileiros, latifundiários, servidores corruptos da Funai e mesmo aos pequenos posseiros lançados sobre as áreas indígenas pelos grupos econômicos (2017, p. 260).

Estas palavras ditas ao final dos anos 1970 ganharam sentido na história dos povos indígenas não apenas para aquela época, mas também no nosso contexto atual. A realidade da aldeia Pakurity- que não difere de muitas outras no estado de Mato Grosso do Sul, bem como em todo território brasileiro - vive uma situação particular de violência, insegurança, luta política pela posse de parte do seu território tradicional e estratégias de sobrevivência que vão brotando a partir desse contexto. Uma história de sofrimento de feroz perseguição e sem descanso.

Os relatos do líder indígena Bonifácio sobre sua vivência no Reformatório Agrícola Indígena Krenak são de suma importância, pois podemos utilizar sua narrativa como forma de marcação de tempo para a construção da história da aldeia Pakurity: desde os tempos em que os indígenas podiam viver livremente em seus territórios, passando pelo esparramo e retomada, até chegar os dias atuais. Assim, os relatos são um instrumento que valida e impulsiona sua luta de resistência, posse e permanência em seu tekoha, seu território tradicional.

Com sua história de "sobrevivência no Krenak" Bonifácio vai além do que os olhos conseguem enxergar e salienta a importância, não apenas do território em si, mas de tudo o que ele representa na cosmovisão Guarani. A divisão do material e do imaterial é feita por nós, os não indígenas, pois para os indígenas eles fazem parte de um todo. $O$ sofrimento suportado em favor de sua coletividade e de sua mãe terra é uma experiência que o fez mais forte e mais sábio. Após seu retorno do Krenak para a permanência na sua aldeia, Bonifácio diz que o mais importante é vivenciar uma vida de igualdade (tekojoja) em que o primordial é retornar ao tekoha e a prática tradicional, vivendo como os antigos. O tekojoja é um ciclo que é transmitido de uma geração a outra, os velhos transmitem às crianças e assim sucessivamente, pois o tekojoja nunca acaba, mas se renova a cada nova geração. Com essa certeza, ele 
continua liderando sua comunidade na concretização da posse do território tradicional para poderem viver de acordo com o teko porã, ou seja, o modo ideal de se viver de acordo com os costumes tradicionais que só pode ser realizado no tekoha. Sem tekoha não há teko porã.

Fica, assim, sua narrativa, que dá título a esse texto, "eu sou prisioneiro do Krenak", a qual remete não apenas ao passado, mas continua no presente, como uma marca indelével do que foi suportado por este líder na luta por seu tekoha.

\section{Referências bibliográficas}

BARBOSA DA SILVA, Alexandra. Mais além da "aldeia": território e redes sociais entre os Guarani de Mato Grosso do Sul. 2007. Dissertação (Mestrado em Antropologia Social) - Programa de Pós-Graduação em Antropologia Social, Universidade Federal do Rio de Janeiro - UFRJ. Rio de Janeiro, [2007].

BORGES, Luciane Chedid Melo. Os termos da meliponicultura: uma abordagem socioterminológica. 2011. 197 f. Dissertação (Mestrado em Letras) - Universidade Federal do Pará. Instituto de Letras e Comunicação, Belém, [2011].

BRAND, Antônio. O confinamento e seu impacto sobre os Pãi/Kaiowá. 1993. Dissertação (Mestrado em História) - Programa de Pós-Graduação em História, Pontifícia Universidade Católica - PUC, Porto Alegre, [1993].

O impacto da perda da terra sobre a tradição Kaiowá/Guarani: os difíceis caminhos da palavra. 1997. Tese (Doutorado em História) - Programa de Pós-Graduação em História, Pontifícia Universidade Católica - PUC, Porto Alegre, [1997].

CAVALCANTE, Thiago Leandro Vieira. Colonialismo, Território e Territorialidade: a luta pela terra dos Guarani e Kaiowá em Mato Grosso do Sul. 2013. 470 f. Tese (Doutorado em História) - Faculdade de Ciência e Letras, Universidade Estadual Paulista - UNESP, Assis, [2013].

CIMI. Relatório: Violência contra os povos indígenas no Brasil: dados de 2010. Disponível em: <http://www.cimi.org.br/pub/MS/Viol_MS_2003_2010.pdf>. Acesso em: 9 de jun. 2016. 
Relatório: Violência contra os povos indígenas no Brasil: dados de 2014. Disponível em: 〈http://www.cimi.org.br/pub/Arquivos/Relat.pdf〉. Acesso em: 3 nov. 2014.

Relatório: Violência contra os povos indígenas no Brasil: dados de 2013. Disponível em: <http://www.cimi.org.br/pub/RelatorioViolencia_dados_2013.pdf >. Acesso em: 3 nov. 2014.

Relatório: Violência contra os povos indígenas no Brasil: dados de 2015. Disponível em: <http://www.cimi.org.br/pub/relatorio2015/relatoriodados2015.pdf > Acesso em: 3 nov. 2016.

CRESPE, Aline C. L. Acampamentos indígenas e ocupações: novas modalidades de organização e territorialização entre os Guarani e Kaiowa no município de Dourados MS: (1990-2009). 2009. Dissertação (Mestrado em História) - Programa de PósGraduação em História, Universidade Federal da Grande Dourados - UFGD, Dourados, [2009].

Mobilidade e temporalidade kaiowá: do tekoha à reserva, do tekoharã ao tekoha. 2015. Tese (Doutorado em História) - Programa de Pós-Graduação em História, Universidade Federal da Grande Dourados - UFGD, Dourados, [2015].

CORRÊA, José Gabriel Silveira. A gestão dos índios e o Reformatório Agrícola Indígena Krenak. 2000. Dissertação (Mestrado em Antropologia Social) - Programa de Pós-Graduação em Antropologia Social, Universidade Federal do Rio de Janeiro - UFRJ. Rio de Janeiro, [2000].

DITADURA criou cadeias para índios com trabalhos forçados e torturas. Carta Capital, 24, jun. 2013. Disponível em: <https://www.cartacapital.com.br/politica/ditadura-crioucadeias-para-indios-com-trabalhos-forcados-e-torturas-8966.html>. Acesso em: 20 mai. 2018.

KEHL, Maria Rita. Violações de direitos humanos dos povos indígenas. In: BRASIL. Relatório final da Comissão Nacional da Verdade - Volume II. 2014. Disponível em: <http://www.cnv.gov.br/index.php/outros-destaques/574-conheca-e-acesse-o-relatoriofinal-da-cnv>. Acesso em: 23 ago. 2016.

LANDA, Beatriz dos Santos. Crianças Guarani: atividades, uso do espaço e a formação do registro arqueológico. In: NASCIMENTO, Adir Casaro do; VIEIRA, Carlos Naglis; AGUILERA URQUIZA, Antonio H. (Org.). Criança Indígena: diversidade cultural, educação e representações sociais. Brasília: Liber Livro, 2011. p. 45 - 74.

LUCAS, Sônia Rocha. Crianças indígenas no acampamento Pakurity - MS: quem são, como vivem e como percebem a situação de moradias móveis. 2017. Dissertação (Mestrado em Antropologia Sociocultural) - Programa de Pós-Graduação em Antropologia, Universidade Federal da Grande Dourados -UFGD, Dourados, [2017]. 
MURA, Fábio. À procura do "bom viver": Território, tradição de conhecimento e ecologia doméstica entre os Kaiowá. 2006. Dissertação (Mestrado em Antropologia) Programa de Pós-Graduação em Antropologia, Universidade Federal do Rio de Janeiro, Museu Nacional, Rio de Janeiro, [2006].

A trajetória dos Chiru na construção da tradição de conhecimento kaiowá. Mana, Rio de Janeiro, v. 16, n. 1, p. 123-150, 2010.

PEREIRA, Levi M. Parentesco e Organização Social Kaiowá. Campinas. 1999. 244 f. Dissertação (Mestrado em Antropologia Social) - Universidade Estadual de Campinas UNICAMP, Campinas, [1999].

Imagens Kaiowá do Sistema Social e seu Entorno. 2004. 345 f. Tese (Doutorado em Antropologia - Etnologia) - Universidade de São Paulo - USP, São Paulo, [2004].

RESENDE. Ana Catarina Zema de. O relatório figueiredo, as violações dos direitos dos povos indígenas no brasil dos anos 1960 e a "justa memória”. In: SIQUEIRA, Gustavo Silveira; WOLKMER, Antonio Carlos; PIERDONÁ, Zélia Luiza (Org.). História do direito. Florianópolis: CONPEDI, 2015.

SCHADEN, Egon. Aspectos Fundamentais da Cultura Guarani. São Paulo: E.P.U./EDUSP, 1974 [1954].

VALENTE, Rubens. Os fuzis e as flechas: história de sangue e resistência indígena na ditadura. São Paulo: Companhia das Letras, 2017.

Recebido em: 30/05/2018 * Aprovado em: 22/10/2018 * Publicado em: 29/12/2018 